\title{
Arsenic's (micro)spatial distribution and speciation in mine wastes: assessing long-term exposure risks at abandoned mines \\ CHRISTOPHER S KIM
}

Chapman University

Presenting Author: cskim@chapman.edu

The historic mining and processing of gold and silver ore deposits throughout the state of California has left an extended legacy of arsenic-contaminated wastes, posing health and environmental threats. The (micro)spatial distribution and chemical speciation of As within waste material particles, though challenging to characterize, holds particular importance for the long-term risk of As exposure as a result of the physical and chemical weathering processes to which mine wastes are exposed over time. Additionally, seasonal effects during dry and rainy seasons can affect As bioaccessibility in ways that may significantly influence risk estimates of chronic As exposure for residents living near mining sites.

A combination of field studies, controlled wetting/drying experiments, particle size-dependent EXAFS studies of As speciation and $\mu \mathrm{XRF}$ spatial mapping with in vitro simulated gastric fluid (SGF) extractions can enable the correlation of As speciation, As spatial distribution, and As bioaccessibility with one another. By additionally pulverizing selected size fractions of the mine waste samples as a proxy for weathering, we can both identify and quantify changes in speciation and assess the extent of physical encapsulation of As as a limiting factor to its mobility. Recent findings from this work include:

- Physical weathering increases As bioaccessibility, although with diminishing effectiveness as particle size decreases, by exposing (reduced) arsenic phases which are more soluble and mobile than surface-bound (oxidized) arsenic phases

- Surface As enrichment in particles is associated with higher As bioaccessibility, while samples featuring interior particle enrichment of As pose a longer-term risk of extended As exposure

- The first known EXAFS examination of samples before and after simulated gastric fluid exposure shows differential removal of As species, with increasing As bioaccessibility correlated with greater removal of species identified as scorodite $\left(\mathrm{FeAsO}_{4}\right)$ and $\mathrm{As}(\mathrm{V})$ sorbed to goethite $(\mathrm{a}-\mathrm{FeOOH})$ but the formation of more crystalline arsenate species.

- Arsenic bioaccessibility in mine sediments is negatively correlated with rainfall, and gradually and progressively increases during dry periods.

These results are expected to significantly improve our ability to predict the role that As speciation and spatial distribution play in controlling As bioaccessibility in contaminated mine wastes over time. 